\title{
La conservación de la autenticidad y la integridad del paisaje cultural como bases de los procesos de gestión
}

Mónica Ferrari | Instituto de Historia y Patrimonio, Facultad de Arquitectura y Urbanismo, Universidad Nacional de Tucumán (Argentina)

Olga Paterlini de Koch | Instituto de Historia y Patrimonio, Facultad de Arquitectura y Urbanismo, Universidad Nacional de Tucumán (Argentina)

URL de la contribución <www.iaph.es/revistaph/index.php/revistaph/article/view/3407>

\section{RESUMEN}

El proyecto de investigación "El Catálogo y las Directrices del Paisaje como instrumentos para el desarrollo regional en la dimensión patrimonial de la Quebrada de Humahuaca, Patrimonio Mundial" tiene por objetivo fundamental contribuir a la preservación y gestión del paisaje cultural de la quebrada de Humahuaca, en Jujuy, Argentina.

El trabajo propuesto ha sido acreditado por la Agencia Nacional de Promoción Científica y Tecnológica de Argentina, dependiente del Ministerio de Educación, Ciencia y Tecnología. Se encuentra en su estado inicial y será desarrollado por profesionales de la Universidad Nacional de Tucumán e instituciones gubernamentales de la provincia de Jujuy.

En la presente contribución se desarrolla brevemente una descripción del patrimonio natural y cultural del sitio, las características de la investigación propuesta como camino para la conservación de la autenticidad y la integridad del paisaje cultural. Se adjuntan, además, algunas consideraciones sobre las complejidades de un sitio patrimonio mundial, así como la importancia de la construcción del inventario y del catálogo guiados por las recomendaciones establecidas por el Convenio Europeo del Paisaje (2000). Finalmente, se señalan los antecedentes, avances y estado del arte.

\section{Palabras clave}

Quebrada de Humahuaca | Paisaje cultural | Patrimonio cultural | Patrimonio natural | Protección | Jujuy, Argentina | Catálogos | Inventarios | 


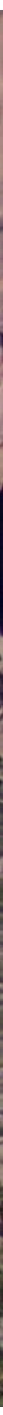




\section{INTRODUCCIÓN}

En la cordillera oriental de los Andes de la región noroeste de Argentina, provincia de Jujuy, se encuentra la quebrada de Humahuaca, fractura geológica cuya altura varía desde los $1.500 \mathrm{msnm}$, en la entrada sur, hasta los $3.000 \mathrm{msnm}$ en el norte. Se trata de un extenso y profundo valle surcado por el río Grande a lo largo de más de $140 \mathrm{~km}$, con un ancho que va oscilando entre 1 y 3 kilómetros. El área ha presentado desde los tiempos geológicos una continuidad geográfico-histórica con el sur de Bolivia y de allí con el altiplano peruano-boliviano, relación que se conservó en los tiempos prehispánicos e hispánicos y comenzó a transformarse a partir de las reformas borbónicas de fines del siglo XVIII, cuando Carlos III creó el Virreinato de Río de la Plata con sede en Buenos Aires. La decisión orientó hacia esta ciudad-puerto el funcionamiento de nuestro territorio, lo que luego se acentuó con el trazado del ferrocarril, a partir de las últimas décadas del siglo XIX (NICOLINI; PATERLINI; SILVA et ál., 1997).

El valle andino ha sido el escenario de gran parte de la evolución de la región y de los países vecinos durante más de 10.000 años, pues ha sido transitado y habitado de forma ininterrumpida desde los primeros pueblos cazadores hasta la actualidad. En tal sentido, ha funcionado como vía permanente de interacción longitudinal y transversal vinculando territorios y culturas distantes y diferentes, desde el Atlántico al Pacífico y desde los Andes a las llanuras meridionales, lo que ha derivado en la conformación de un paisaje cultural en el que se distinguen componentes patrimoniales

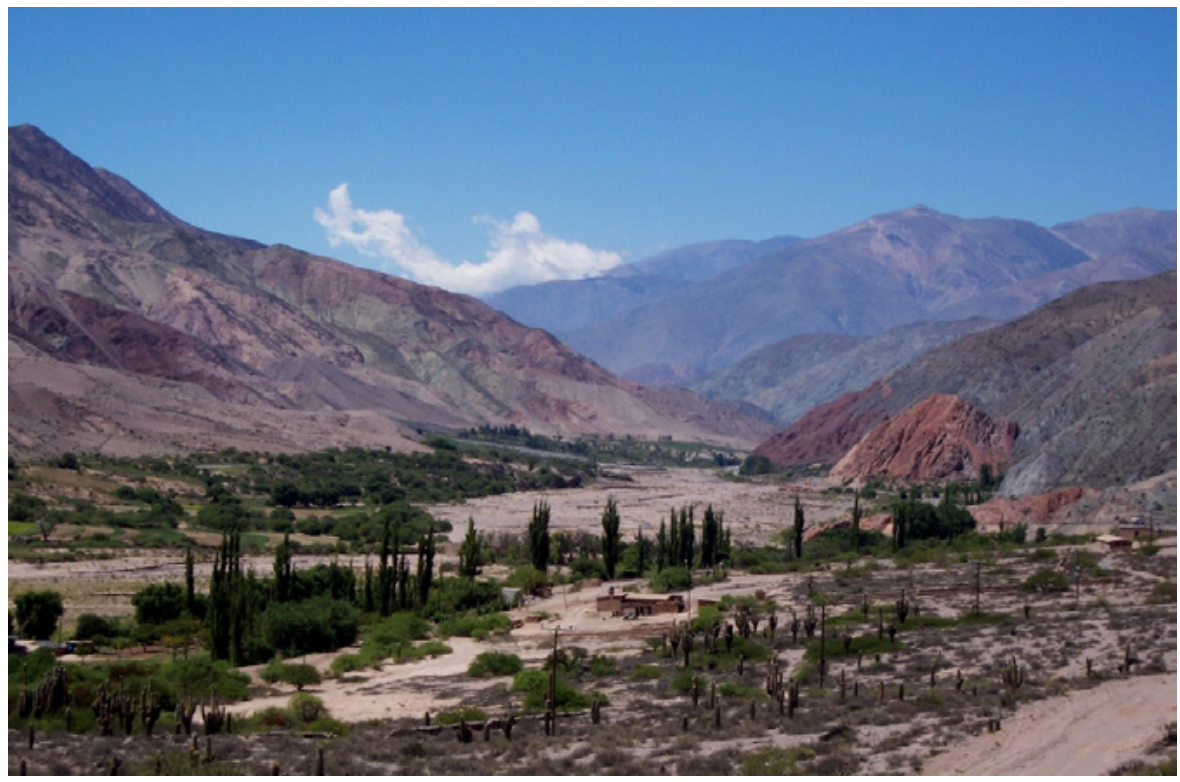

Valle del Río Grande en la Quebrada de Humahuaca | foto Mónica Ferrari 

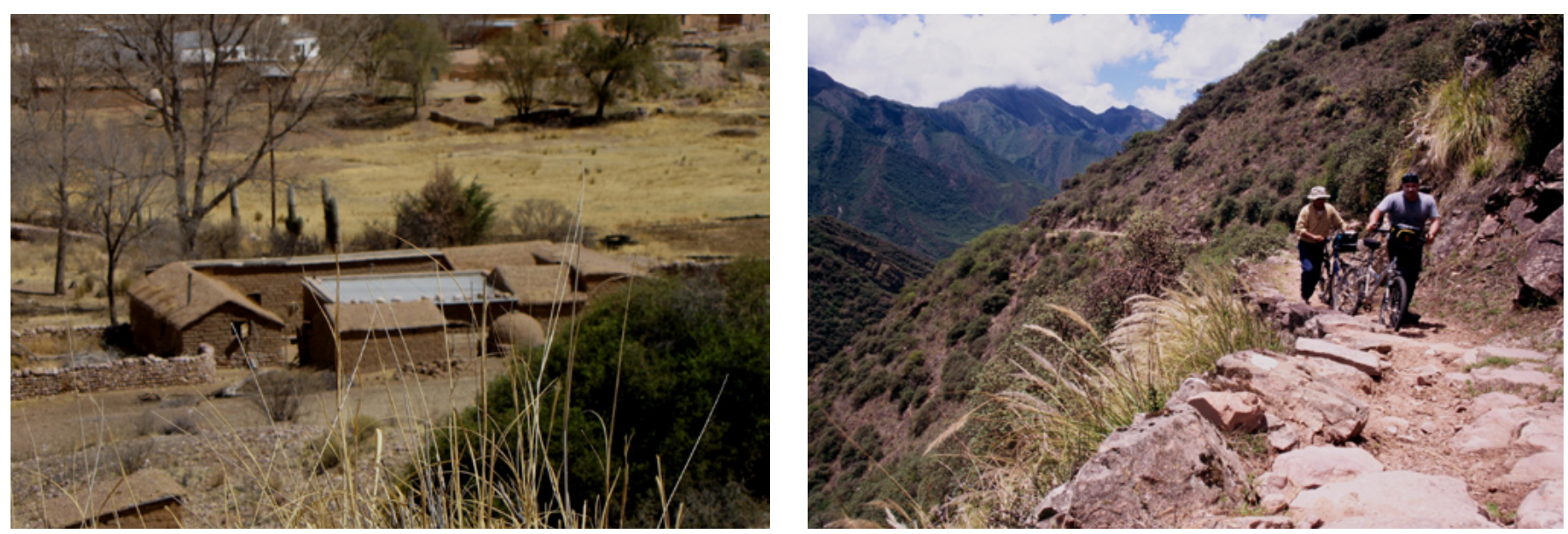

Vivienda rural cerca de Rodero | foto Mónica Ferrari

tangibles e intangibles que reflejan la historia cultural de la región (JOSÉ et ál., 2002: 13).

En el año 2003, el área fue declarada patrimonio mundial en la categoría de paisaje cultural; el legajo de la postulación constituye un documento de particular interés para comprender las características y valores de la Quebrada, pues sintetiza un sinnúmero de investigaciones que han abordado su estudio desde hace varias décadas, al tiempo que genera una nueva lectura con perspectiva patrimonial que ha permitido, por ejemplo, establecer el área de mayor protección en aproximadamente 172.000 ha y una zona de amortiguación de 365.000 ha (JOSÉ et ál., 2002: 16).

Los elementos clave que integran el patrimonio pertenecen por partes iguales tanto a la naturaleza como a la obra del hombre. Esto concilia con notable equilibrio las tierras de cultivo con las viviendas dispersas o los conjuntos poblados (NICOLINI; PATERLINI; SILVA et ál., 1997). En ese contexto destaca, por ejemplo, la red de vías de tránsito integrada por caminos prehispánicos, hispánicos, republicanos y de la modernidad reciente, que fueron conformando el sistema de comunicaciones que enlazaron y enlazan a su paso un número importante de recursos paisajísticos de diversos valores y escalas. Así, gran parte del espacio de la Quebrada se encuentra surcado por estrechas sendas de montaña que articulan sectores del paisaje con el eje del río Grande, vinculando los poblados, caseríos, campos de cultivos, puestos y áreas de pastoreo, abrevaderos para el ganado, áreas de extracción de leña, etc. Muchas de estas huellas corresponden a antiguos derroteros que fueron reutilizados en forma recurrente a lo largo de los siglos. El sistema, por lo tanto, se halla en una interdependencia de elementos patrimoniales que lo singularizan y que forman parte de un proceso dinámico en constante evolución. Camino antiguo peatonal empedrado entre valle
Colorado y Santa Ana | foto Mónica Ferrari 


\section{EL PATRIMONIO NATURAL DE LA QUEBRADA DE HUMAHUACA}

El río Grande ha constituido el eje articulador natural y cultural en el ámbito de la Quebrada. Tiene sus nacientes en los arroyos de la Cueva y de Tres Cruces, en los límites orientales de la Puna, que se unen próximos a la localidad de Iturbe, a $3.340 \mathrm{~m}$ de altitud y, desde allí, ya como río Grande, el curso de agua recorre una extensión de aproximadamente $144 \mathrm{~km}$ en sentido norte-sur hasta su confluencia con el río Reyes a una altitud de 1.350 m. Hacia el oeste, el límite entre la Puna y la cordillera oriental es la divisoria de aguas entre las cuencas intermontanas puneñas y las tributarias del río Grande. Este límite, a nivel geográfico, está determinado por la sierra de Aguilar $(5.000 \mathrm{~m})$, la sierra del Alto y la sierra de Chañi, que culmina con el nevado de Chañi $(6.200 \mathrm{~m})$; hacia el este, está representado por las estribaciones orientales de las sierras de Santa Victoria, Zenta y Tilcara, y el sector septentrional de las sierras de Zapla.

El río Grande es una depresión longitudinal producto de la erosión hídrica, al que desembocan las quebradas transversales y los afluentes. Por la margen derecha recibe los ríos Sapagua, Coraya, Cuchiyaco, Yacoraite, Queta Cara Chico, Jueya, Huichaira, Hornillos, Purmamarca, Tumbaya, Coiruro, arroyo del Medio, León, Lozano, Yala y Reyes. Sobre su margen izquierda recibe al Chaupi-Rodero, Coctaca, Calete, la Huerta, Huasamayo, Punta Corral y Huajra. Con excepción de los ríos León, Lozano, Yala y Reyes, los demás sólo aportan caudal superficial durante las grandes tormentas permaneciendo el resto del tiempo prácticamente secos, ya que los reducidos cau-

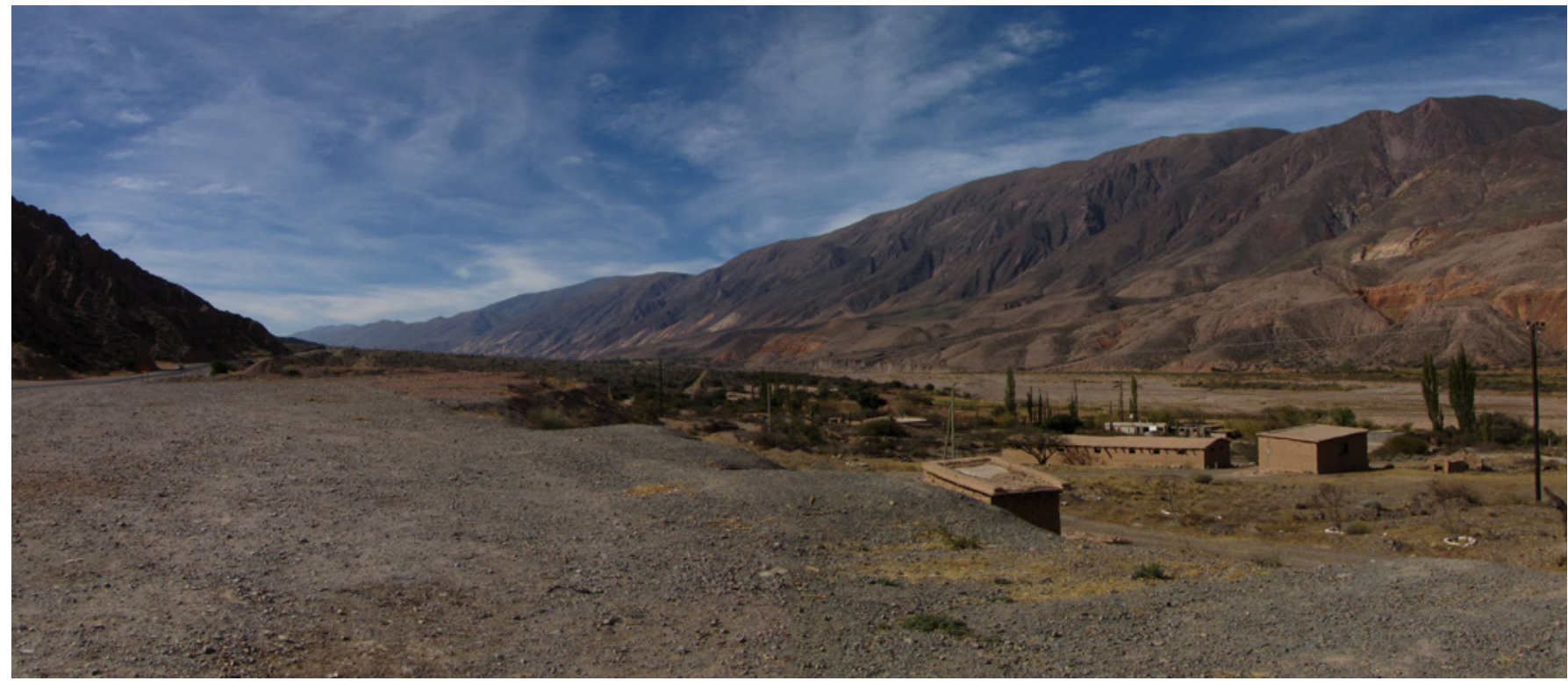


dales son derivados para riego (JOSÉ et ál., 2002: 58). El río vertebra todo el conjunto y zigzaguea suavemente cambiando el ancho de la vaguada, lo que individualiza a cada sector, a lo que se agregan ramificaciones de los pequeños valles como el de Purmamarca (NICOLINI; PATERLINI; SILVA et ál., 1997).

La quebrada de Humahuaca constituye un territorio privilegiado en cuanto a la diversidad y riqueza de su registro geológico; sus numerosas estructuras expuestas a la acción fluvial presentan estratos, plegamientos y procesos erosivos que van desde el Precámbrico (hace más de 600 millones de años) hasta los depósitos más recientes del cuaternario. El área se puede clasificar en cuatro grandes unidades geomorfológicas: a) terrazas que afloran en ambas márgenes del río; b) morfología propia de la acción erosiva del agua y escorrentías de los tributarios; morfología de tubos de órganos en los distintos niveles de terrazas aluviales de Tumbaya; paisaje de cárcavas de sedimentos terciarios cuaternarios de Hornillos-Maimará; c) depósitos lacustres que evidencian importantes cambios climáticos en algunos sectores de la cuenca del río Grande y su asociación en procesos de remoción en masa como deslizamientos rotacionales propios de depósitos limo-arcillosos; d) abanicos aluviales en formación, entre los cuales se destaca el abanico aluvial del arroyo del Medio (JOSÉ et ál., 2002: 53).

Los procesos de remoción en masa, característicos en la Quebrada, se generan por la acción conjunta de distintos factores: pendiente, cubierta vegetal, litología y clima. Los más significativos son los flujos o torrentes
Vista del arroyo del Medio desde el puente que lo cruza | foto Mónica Ferrari

Cono de deyección entre el borde del río y el pie de la montaña | foto Mónica Ferrari
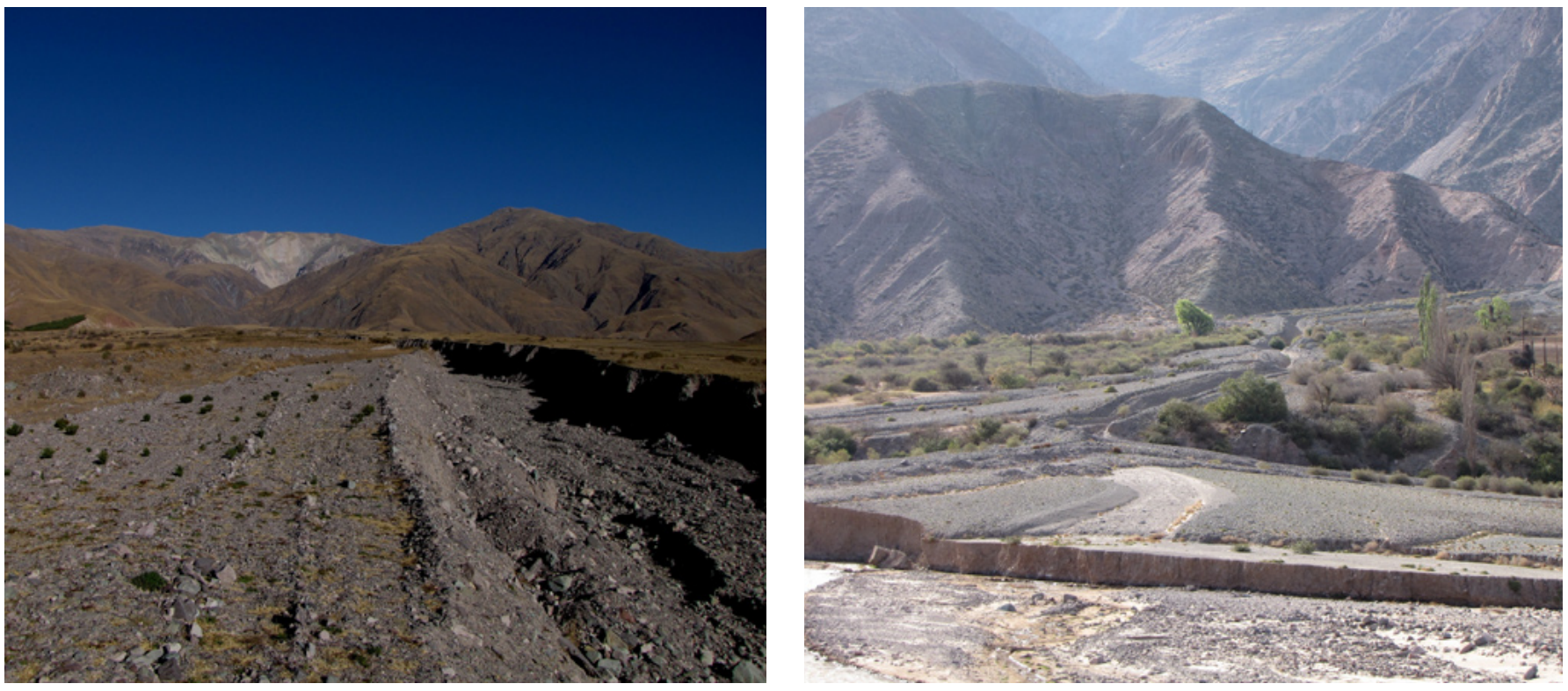

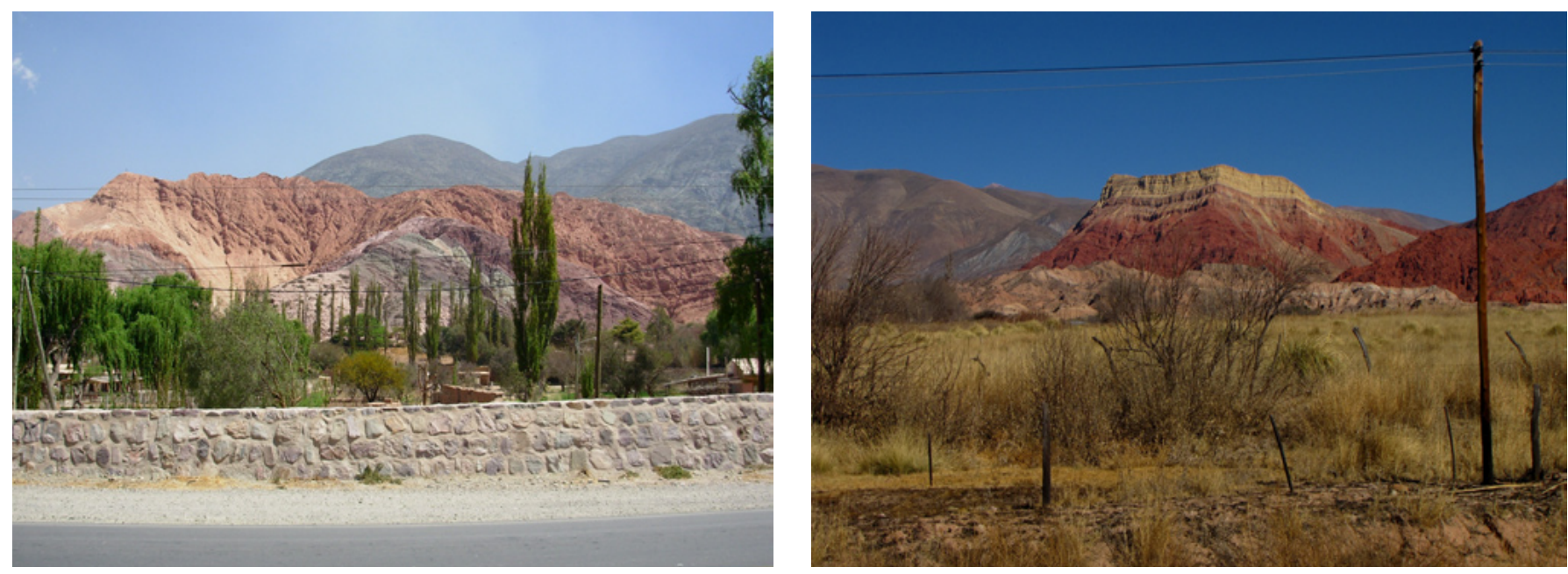

Cerro de los Siete Colores y cerro de la Pollerita | fotos Mónica Ferrari

de barro localmente denominados "volcanes". El importante aporte sedimentario de estos fenómenos ha determinado la formación de enormes conos de deyección que se deslizan hacia el río como los de Coiruro, Huajra, Hornillos, Huichaira, Guasamayo y Cuchiyaco (JOSÉ et ál., 2002: $67)$.

Los accidentes naturales, fundamentalmente los de la orografía, introducen peculiaridades de altura y de lejanía de horizonte; en la cercanía, de color y textura, a veces asombrosos; el clima, de gran sequedad, según el lugar, matiza las condiciones de la latitud subtropical. Las lluvias y el viento tallan la montaña en formas muy variadas, a veces inverosímiles (NICOLINI; PATERLINI; SILVA et ál., 1997). Son de una gran riqueza estética los cerros de los Siete Colores, Paleta de Pintor y la Pollerita.

Los "angostos" constituyen un rasgo característico de la morfología de la Quebrada pues determinan un importante estrechamiento del fondo de valle. Estos accidentes geográficos han tenido gran importancia para la conformación del recorrido en la Quebrada, al configurarse como espacios obligados de tránsito. En ellos pueden reconocerse orígenes morfológicos o estructurales; los primeros se forman por la acción continua de los avances de los flujos de barro y/o detritos que determinan la formación de importantes abanicos o conos aluviales ya citados. Los estructurales, en cambio, dependen de la morfología de serranías que definen la cuenca del río Grande y son resultado de la acción tectónica compresiva que durante su evolución (Paleozoico Inferior-Cenozoico) ha fracturado y plegado a las rocas. Algunos "angostos" conforman hitos significativos en el paisaje, como el angosto de Perchel que otrora cumplió la función de límite sociopolítico entre dos importantes parcialidades prehispánicas de la zona: los Tilcara y los Omaguaca (JOSÉ et ál., 2002: 68-69). 

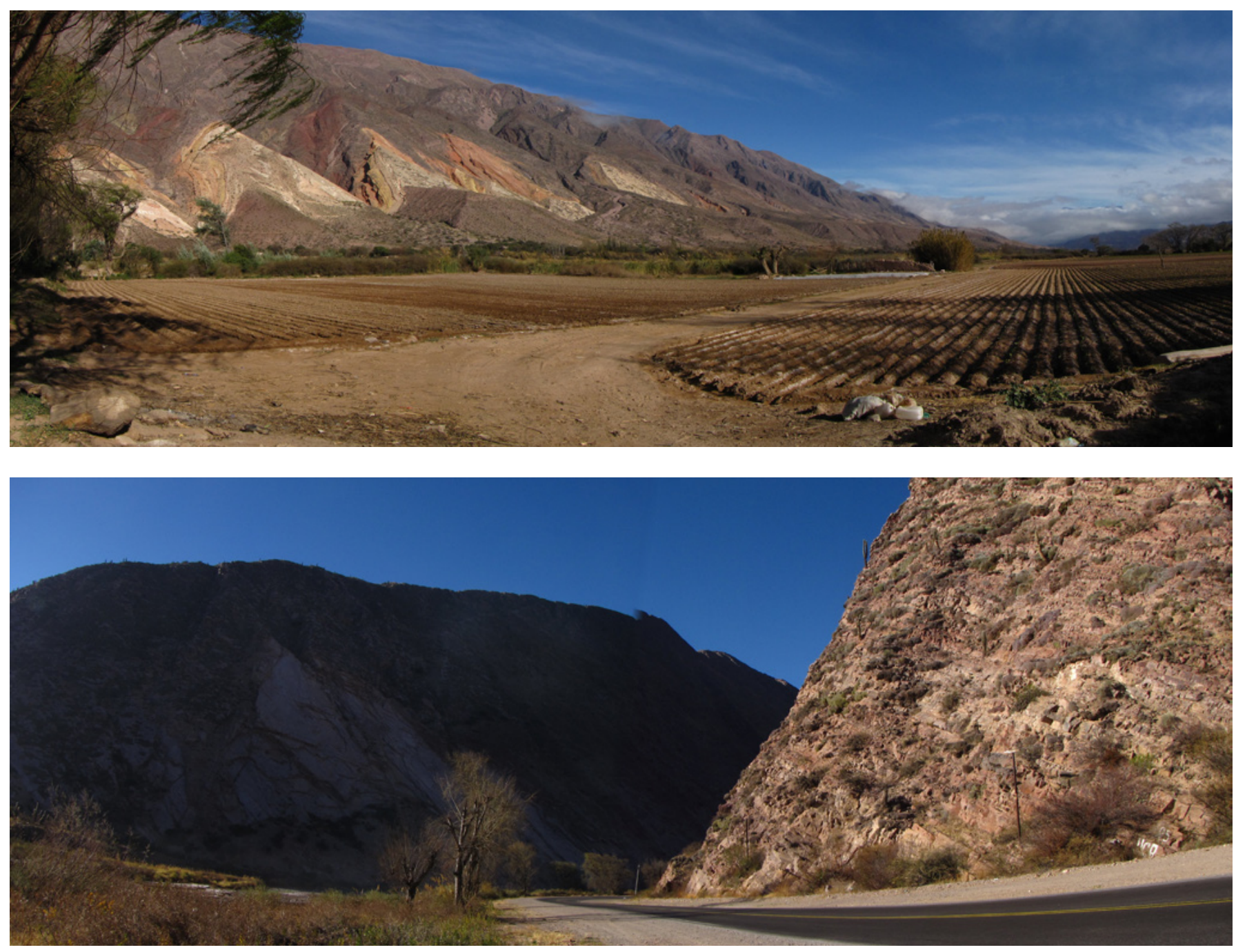

Cerro Paleta de Pintor y angosto del Perchel | fotos Mónica Ferrari

Otra de las características del paisaje quebradeño son las vegas y ciénegos que se usan como sitios de pasturas naturales. La primeras se vinculan con vertientes ubicadas en las partes altas de la serranía y dan lugar a la formación de un tapiz herbáceo bajo y muy denso. Esta vegetación es permanente y se utiliza como pastura para los animales domésticos. Ocasionalmente, estos sitios pudieron ser utilizados como lugares de alimentación del ganado en pie. Los "ciénegos" definen sectores del fondo del valle donde existen importantes vertientes de agua. Allí, la escasa pendiente permite el anegamiento del suelo y el surgimiento de diferentes comunidades vegetales. Estos espacios, que en algunos lugares ocupan superficies considerables (al norte de Tilcara, en las inmediaciones de Campo Morado y en Uquía), también son utilizados como pasturas para los 


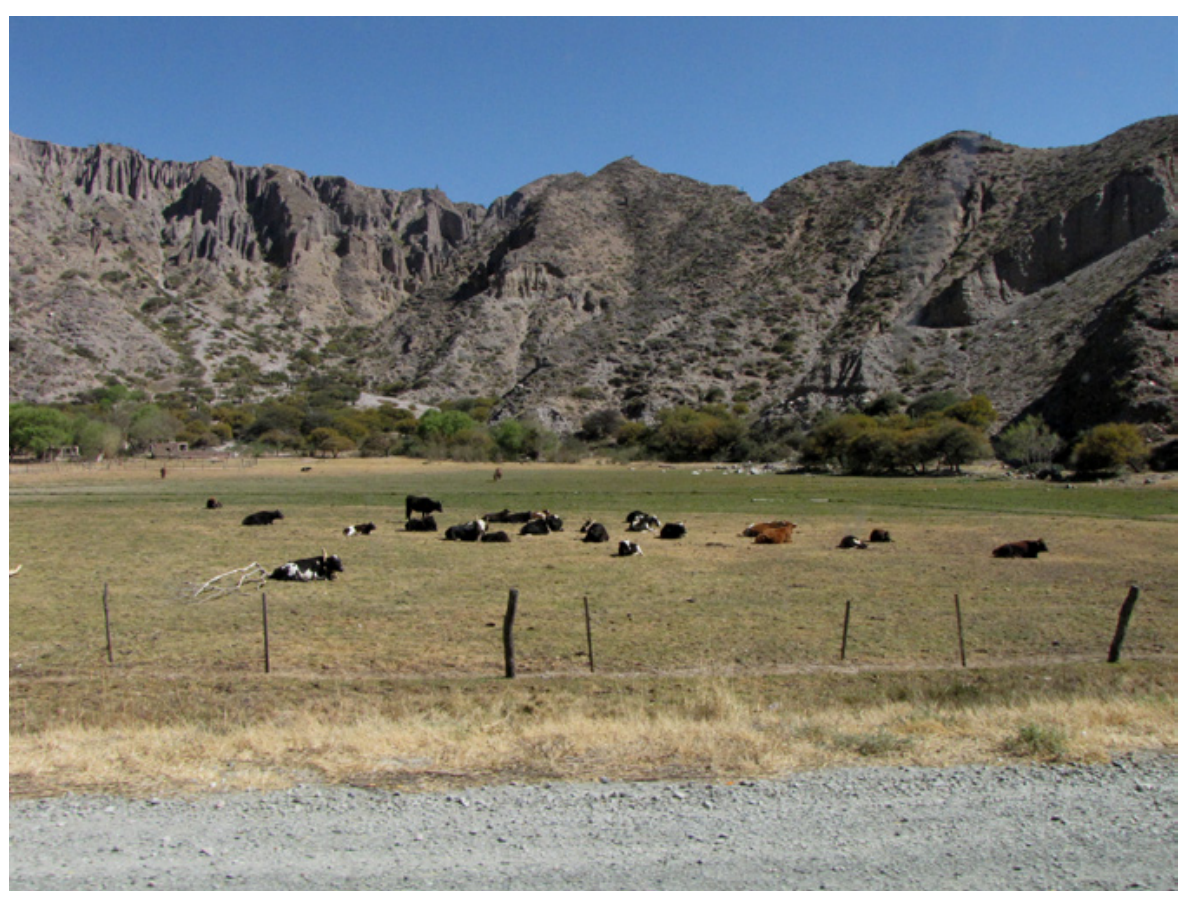

Tierras de pastoreo | foto Mónica Ferrari

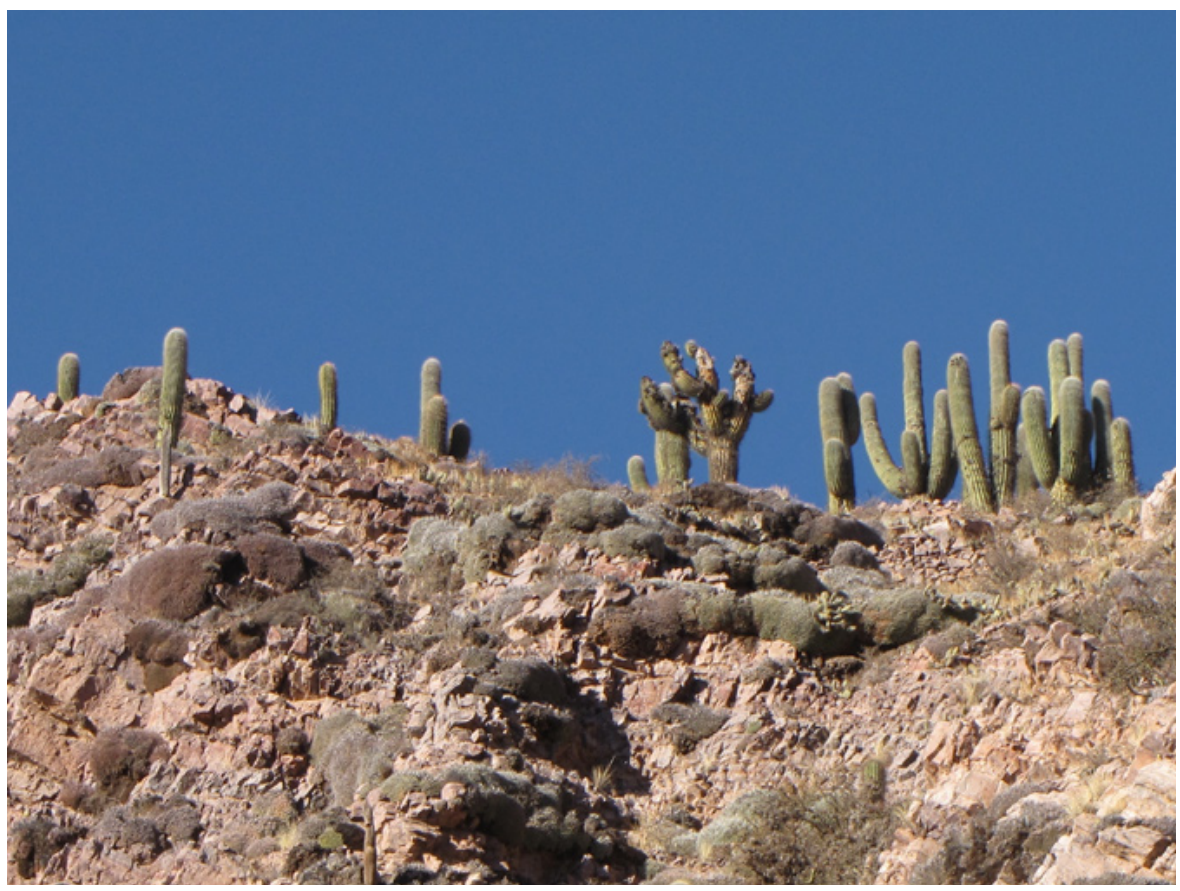

Cardonales en el Perchel | foto Mónica Ferrari 
animales domésticos y es probable que tuvieran un rol muy importante en la época del traslado de ganado en pie por su proximidad a los espacios de circulación (JOSÉ et ál., 2002: 71).

La quebrada de Humahuaca es un territorio privilegiado en cuanto a la diversidad y riqueza de flora y fauna; integradas en tres dominios fitogeográficos (amázonico, chaqueño y andino patagónico) y cuatro provincias (Yungas, Prepuna, Puna y Altoandino), ofrecen variedad de ricos microambientes distribuidos en forma de parches en su extensa superficie. En un recorrido pausado por el territorio, despierta singular atención la visual hacia los cardonales (Trichocereus sp.) cuya máxima expresión se observa en las laderas de la quebrada de Calete. En el norte de la Quebrada, entre Uquía y Chorrillos, destaca la asociación de dos especies, el "cardonal" y el "churcal", que otorgan una fisonomía particular y característica de este escalón superior de la Prepuna. El noreste de la Quebrada configura otro sector destacable desde el punto de vista paisajístico con su vegetación de estepa arbustiva puneña y altoandina (JOSÉ et ál., 2002: 59-60).

\section{LA QUEBRADA COMO EXPRESIÓN CULTURAL}

Las diversas miradas de aproximación al estudio de un territorio ya como "paisaje cultural" permiten percibir el amplio espectro que genera el hombre imbricado con su contexto natural lo que define, a su vez, múltiples ejes de aproximación para explicitar las cualidades paisajísticas intrínsecas, legibles y comprensibles que posee. Es por eso que también se suele caracterizar al paisaje como la "articulación entre lo físico, lo biológico y lo cultural en cada lugar"; "espacio en el cual se expone la relación entre la sociedad y su territorio"; "ámbito de encuentro, de diálogo y de creatividad"; "lugar resultado de la relación sensible de la gente con su entorno percibido, cotidiano o visitado", para citar sólo algunas de las referencias (PATERLINI, 2012). Estas aproximaciones pueden verificarse en la quebrada de Humahuaca mediante el reconocimiento de sus recursos que, como conjunto, constituyen un palimpsesto indiscutible.

Así, por ejemplo, de las huellas que el hombre ha dejado de su fase nómada hace más de 10.000 años cuando finalizaba la era de los hielos o Pleistoceno se observan abrigos y cavernas prehistóricas de los cuales Huachichocana e Inca Cueva son los más fieles testimonios. El sedentarismo llevó a que en la quebrada de Humahuaca se localizaran los agricultores y pastores del Período Formativo de lo que quedan testimonios como Antumpa, Estancia Grande, el Alfarcito y el área urbana de Tilcara. Durante el período de los Desarrollos Regionales, a finales del primer milenio después de Cristo, la era de los guerreros trajo aparejado cambios significativos en el paisaje al generar recintos fortificados en línea reconocidos como "pucaras" que 
se prolongaron a lo largo de kilómetros, manifestaciones que no han sido registradas en otros contextos del espacio andino. Los pucaras se destacan por su emplazamiento en el paisaje, al estar próximos al río, elevados y muy visibles desde áreas adyacentes, con contactos visuales entre sí. Se suman a ellos complejos sistemas arquitectónicos, ceremoniales y agrícolas. Entre 1430 y 1536, el sitio declarado patrimonio mundial quedó integrado al Imperio inca y la comunidad no pudo resistir la superioridad económica y militar del Tawantinsuyo; el complejo agrícola de Coctaca y la red incaica -el Capacñam-, con su camino principal y ramales secundarios, fueron las intervenciones más destacadas (BOSCHI; NIELSEN, 2004: 11-64; JOSÉ et ál., 2002: 29).

En la etapa de la ocupación hispánica, la quebrada de Humahuaca se convirtió en la ruta de acceso de los españoles que venían del alto Perú. El territorio fue organizado en función de mercedes, encomiendas y reducciones, donde se fueron estableciendo enclaves rurales y "pueblos de indios", dando lugar a las actuales poblaciones de Tumbaya, Purmamarca, Huacalera, Humahuaca y Uquía. Arquitectónicamente, los edificios religiosos responden a la tradición mudéjar y las viviendas se organizan en los pueblos como "casas a patios", lo que se observa también en las postas, las haciendas y los molinos, mientras los caseríos tienden a conformarse alrededor de un patio de labor en los asentamientos rurales que van ocupando el territorio para la práctica agrícola-ganadera (BOSCHI; NIELSEN, 2004: 70).

La región fue escenario de las guerras de la independencia y, ya conformada la república, se dio paso a la organización civil de los antiguos pueblos de indios, entre ellos Purmamarca, lo que significó su sistematización y delineado. Con el trazado de la línea del ferrocarril, en los primeros años del siglo XX, se creó una nueva serie de pueblos con un sistema de estaciones, puentes ferroviarios y otras obras de arte distribuidas en el territorio que, con particular calidad, dejaron su impronta en el paisaje; estas acciones fueron consolidando el modelo de funcionamiento regional que incluía a los países vecinos, como había ocurrido desde antaño. El modelo de ocupación recibió un nuevo incentivo cuando se trazó la red vial que caracteriza hoy a la región y que fue reproduciendo el camino de las postas y el trazado ferroviario.

El habitante de la Quebrada decantó hábitos y procedimientos a través de los siglos, que denotan una sabiduría profunda en la construcción de su hábitat. La producción arquitectónica incluye una selección con criterio del sitio para el emplazamiento de las construcciones, buscando siempre obtener las mayores ventajas del entorno natural, protegiéndose de los vientos, aprovechando el asoleamiento, las variaciones climáticas estacionales, los materiales naturales para la construcción, entre otros, lo que se traslada también al uso de la parcela urbana en la cual se hace reserva de casi un tercio de su superficie para quinta para activarla como una unidad productiva. Las técni- 

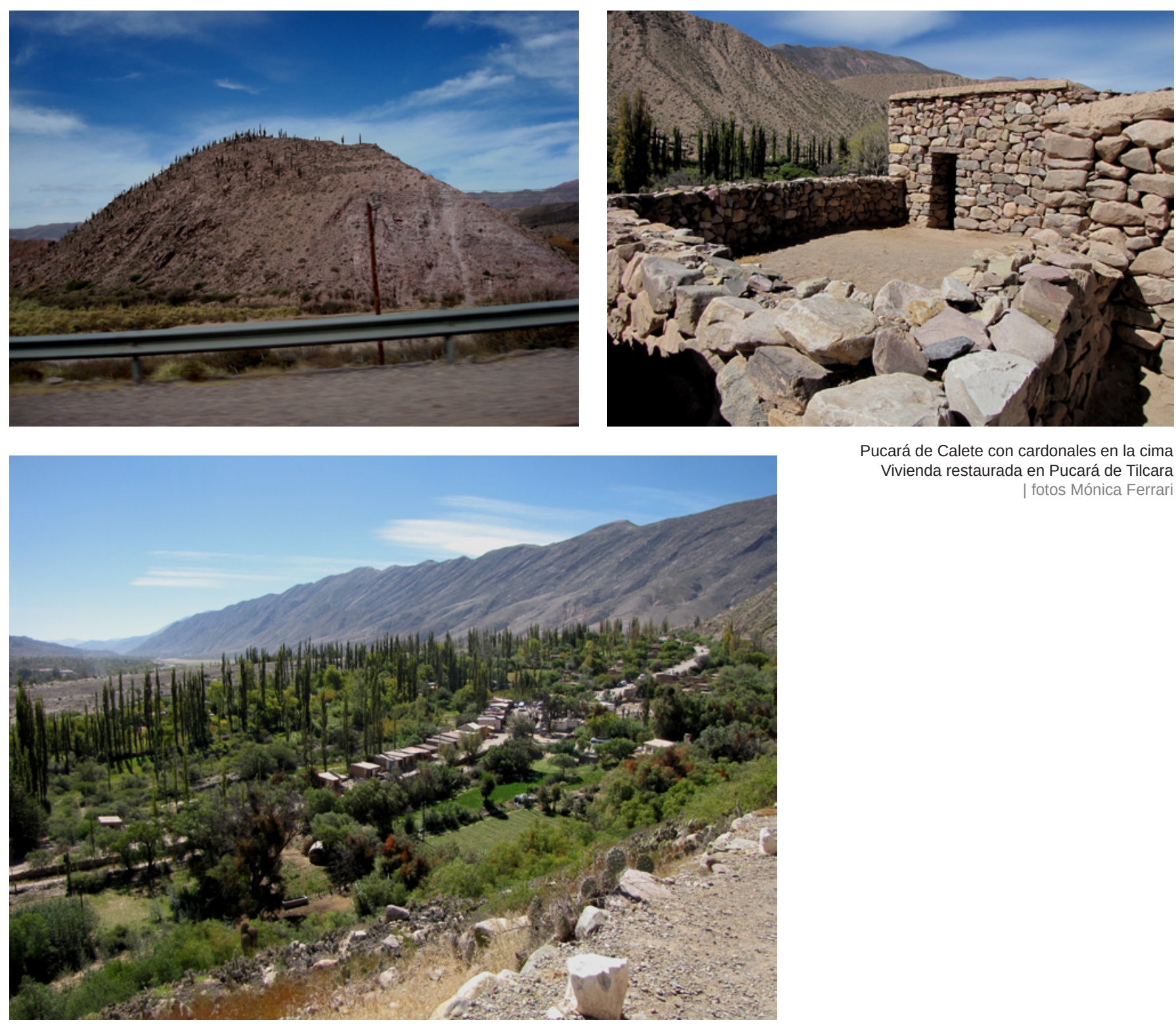

Vista del valle del Río Grande desde el Pucará de Tilcara | foto Mónica Ferrari

cas y procedimientos vinculados a la construcción de la arquitectura han ido perfeccionándose a partir del empleo de los materiales con predominio de la tierra cruda, la piedra y los vegetales; la transmisión del conocimiento se realiza entre artesanos de la construcción, de generación en generación. Cabe sin embargo acotar que, desde hace casi dos décadas y en particular a partir de la declaratoria de UNESCO, la radicación creciente de profesionales vinculados a la arquitectura ha permitido fortalecer estas técnicas perfeccionándolas con los avances tecnológicos contemporáneos. Este proceso les ha permitido generar una mayor efectividad en su aplicación, lo que ha posicio-
Pucará de Calete con cardonales en la cima Vivienda restaurada en Pucará de Tilcara | fotos Mónica Ferrari 
De izquierda a derecha, de arriba abajo, pueblo de Tumbaya | foto Mónica Ferrari

Pueblo de Purmamarca, al fondo se observa el cerro de los Siete Colores | foto Mónica Ferrari

Iglesia de Tumbaya | foto Mónica Ferrari

Procesión durante la fiesta de Nuestra Señora de la Asunción en Casabindo | foto Mónica Ferrari nado nuevamente a estas técnicas, situación muy valiosa en momentos en que el uso del adobe o de la torta de barro comenzaba a ser reemplazado por el bloque de hormigón y la chapa de cinc (ROTONDARO et ál., 2012: 2).

Respecto al patrimonio intangible es necesario mencionar la diversidad de manifestaciones culturales que caracterizan a los habitantes quebradeños, como las fiestas del carnaval y de la Semana Santa, las manifestaciones religiosas en general y las celebraciones cívicas en las fiestas patrias. También la música, el lenguaje de los pueblos originarios, los tejidos con el empleo de fibras y teñidos naturales, el afloramiento de las comidas regionales y con ello de los productos como la quinoa que utilizaron los pueblos prehispánicos, así como otras expresiones de la vida cotidiana, de los sistemas productivos como la agricultura y la cría de animales, los que en conjunto representan la fructífera colaboración entre pueblos y culturas diversas y constituyen
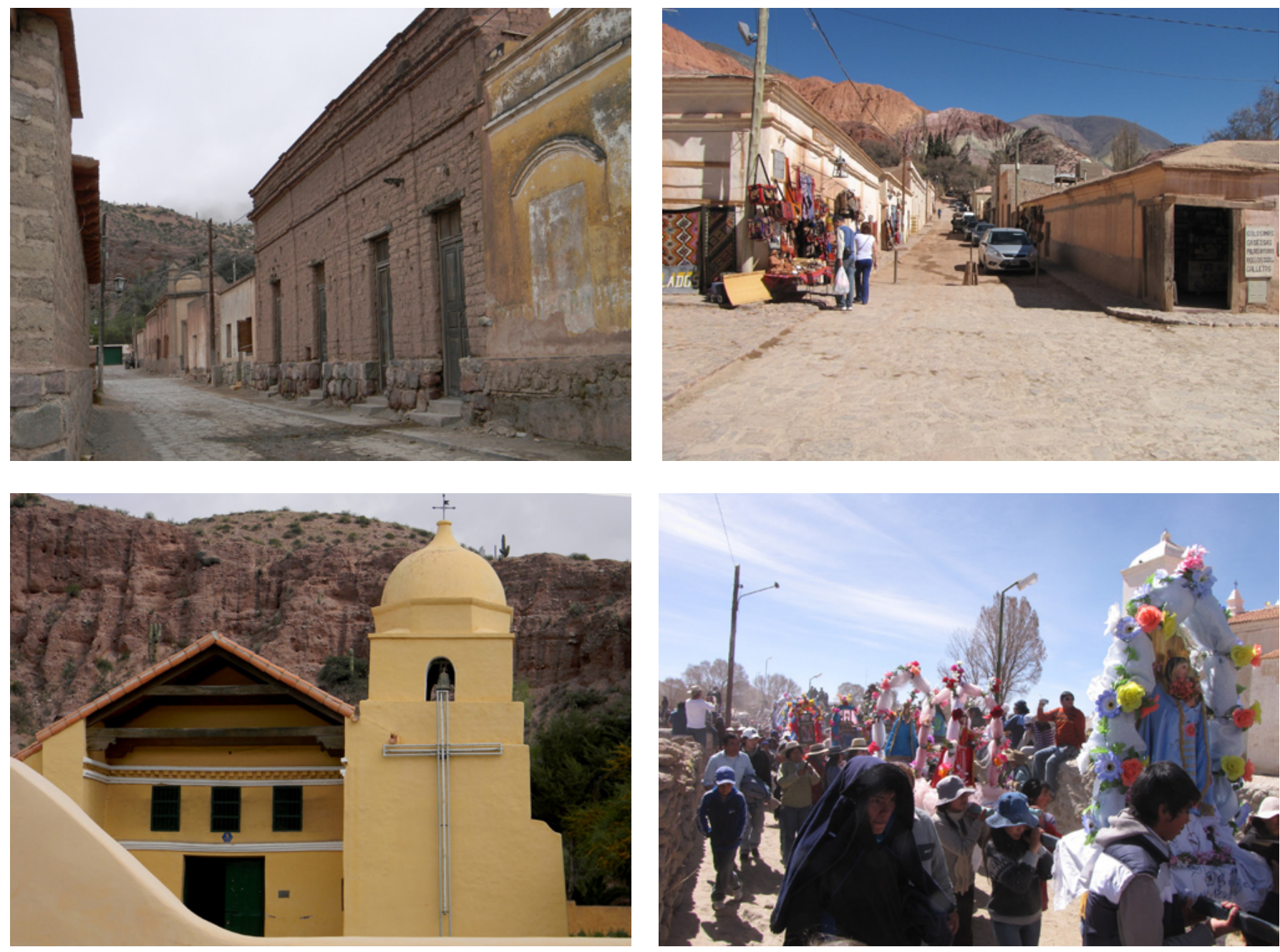
legados inmateriales de este paisaje cultural (JOSÉ et ál., 2002: 14). Cobra especial interés mencionar la fiesta de Nuestra Señora de la Asunción, que se celebra en Casabindo cada 15 de agosto, donde se se conmemora la Asunción de la Virgen María, se realizan ofrendas a la Pachamama en una celebración popular de procesión, danza de Samilantes, y el Toreo de la Vincha.

El reconocimiento de UNESCO a la región como paisaje cultural patrimonio mundial en 2003 , así como los profundos cambios económicos y sociales por los que transitó el país en los primeros años del nuevo milenio, ha motivado una transformación acelerada y con fuerte impacto en el territorio, contraria a su proceso histórico de orgánica y lenta evolución. Al proceso global, se han sumado en lo local factores como el turismo y la construcción a escala masiva de los planes federales de vivienda popular. Con relación a ello se observa que se han formulado planes provinciales y nacionales para orientar la actividad turística, situación que no se ha repetido respecto de la planificación territorial que permitiría orientar las transformaciones sin afectar la autenticidad e integridad del paisaje, es decir, los valores excepcionales que le permitieron ser reconocido como patrimonio mundial (PATERLINI; FERRARI, 2011: 3).

\section{LA INVESTIGACIÓN COMO CAMINO PARA LA CONSERVACIÓN DE LA AUTENTICIDAD Y LA INTEGRIDAD DEL PAISAJE CULTURAL}

El momento histórico por el que transitamos requiere generar un proceso de gestión tendente al conocimiento detallado de los valores patrimoniales de la quebrada de Humahuaca como paisaje cultural para generar la conservación de sus valores y orientar su desarrollo. Partimos de comprender como paisaje cultural un ámbito geográfico que contiene valores naturales y culturales que se definen según la percepción que los habitantes tienen de su territorio. El concepto remite a los temas de patrimonio e identidad pues considera las relaciones entre la sociedad y su espacio vital, así como las interacciones complejas, dinámicas y cambiantes que se generan de acuerdo con los procesos sociales y económicos. Cabe destacar que diversos países poseen valiosos paisajes culturales a nivel mundial, lo que llevó a la UNESCO a establecer la categoría en 1993; desde entonces, se han protegido más de 30 sitios.

La planificación actual del territorio considera a los paisajes culturales un activo de gran importancia para el desarrollo económico-social; sin embargo, su identidad y conservación se ve amenazada por procesos de transformación asistemáticos e inorgánicos en el marco del llamado "desarrollo". Al mismo tiempo, la creciente participación de la comunidad en los cambios sociales, políticos y del paisaje ha conducido a que la valoración de los terri- 
torios trascienda el ámbito académico y profesional para involucrar a sus pobladores. De acuerdo con ello, sostenemos en este proyecto que el paisaje cultural conforma un bien colectivo al que es necesario "re-conocer" y salvaguardar y que toda intervención se posiciona como el derecho de las comunidades a proteger su forma de habitar, tanto en la calidad como en la cualidad y bajo la consideración de proceso de evolución social.

Frente a esta problemática, la conservación de los paisajes culturales se ha visto fortalecida por diversas normativas de orden internacional relacionadas con el desarrollo sostenible, especialmente cuando, en el año 2000, el Convenio Europeo del Paisaje instó a los países a trabajar colectivamente en su planificación, protección y gestión. Esto produjo un interés generalizado en varios los Estados hacia la revitalización o regulación de porciones del territorio tomando como soporte su acervo cultural y natural, identificando para una gestión adecuada tanto a los paisajes con alto valor como a los de escaso valor o los degradados. Estas acciones fueron incentivadas por la normativa europea, así como la preocupación por una gestión orientada hacia el desarrollo sostenible.

En Argentina, la quebrada de Humahuaca en Jujuy se encuentra inmersa en esta problemática. En efecto, a partir de 2003, momento de la declaratoria, sólo tres años después del Convenio Europeo, la patrimonialización de la región se presenta como una oportunidad para el desarrollo regional sustentado en el acervo cultural. La situación constituye al mismo tiempo una amenaza, debido a una serie de razones: a) por el creciente desarrollo del turismo y la construcción de diversos equipamientos vinculados a la actividad; b) la falta de legislación referida a la protección del patrimonio y para orientar la construcción en los pequeños pueblos; c) la ausencia de estudios referidos al paisaje cultural que orienten el accionar en el territorio a través
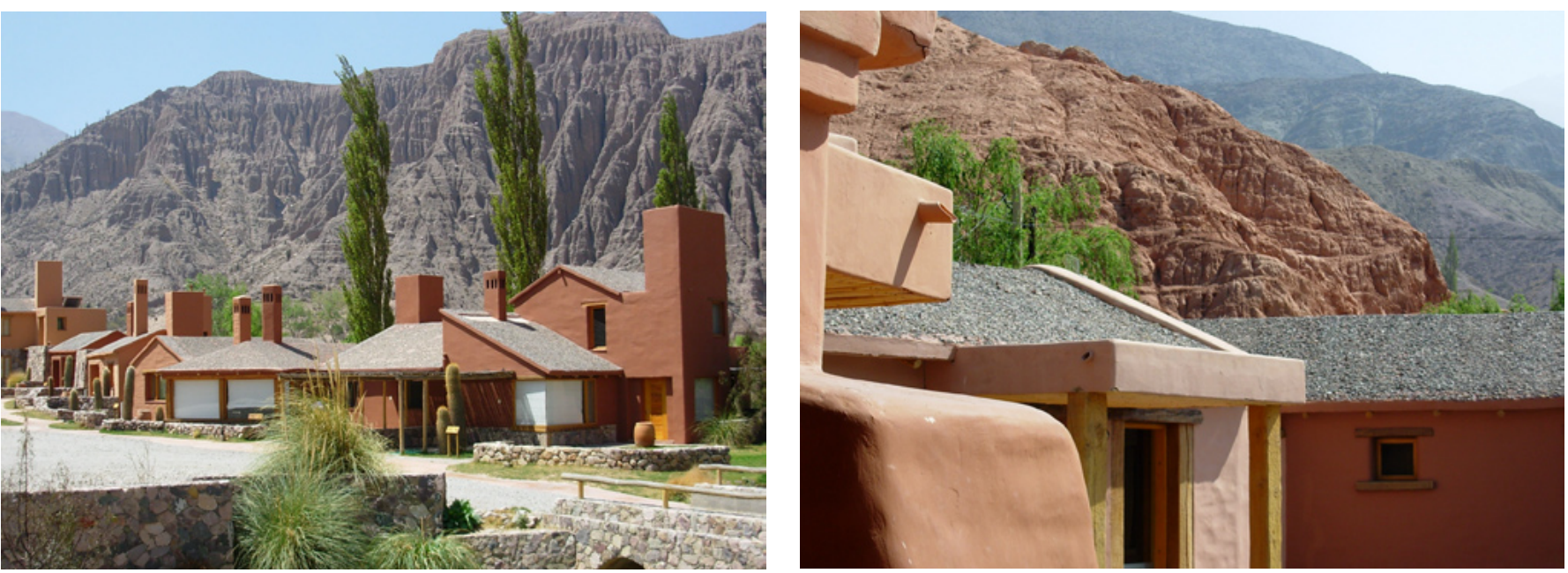
de directrices y de planificaciones; d) la falta de inventarios y catálogos accesibles a las comunidades para el conocimiento de su patrimonio, entre otros múltiples factores; e) la construcción de equipamientos comunitarios sin la consideración del paisaje y de sus valores patrimoniales.

Con el fin de contribuir a la integración de dos posiciones que en principio parecieran contrapuestas, la salvaguarda de los recursos paisajísticos patrimoniales y el desarrollo económico-social del territorio para ajustarse a los requerimientos contemporáneos, es objetivo general de este proyecto: desarrollar un sistema de gestión del paisaje cultural de la quebrada de Humahuaca, requisito establecido por UNESCO en la Declaratoria como Patrimonio Mundial, con el objeto de establecer líneas directrices que orienten el accionar hacia el desarrollo local y regional, implementando un proceso operativo de participación comunitaria que integre a los habitantes a través de sus organizaciones civiles, a los representantes del sector público y privado y a las áreas académicas. El proceso de gestión se realizará a través del desarrollo de instrumentos operativos definidos como inventario de recursos paisajísticos y catálogo del paisaje cultural.

\section{LAS COMPLEJIDADES DE UN SITIO DE PATRIMONIO MUNDIAL. IMPORTANCIA DEL INVENTARIO Y DEL CATÁLOGO}

La necesidad de organizar el inventario y el catálogo del patrimonio con alta participación de la población está presente en el Plan Nacional de Desarrollo Turístico Sostenible 2016. Hasta la fecha, se han realizado algunos intentos sin lograr avanzar en la identificación de los recursos de este complejo territorio, pero transcurridos 10 años de la declaratoria, el propósito se transforma en una necesidad prioritaria a resolver. Algunos sectores han abor| foto Mónica Ferrari
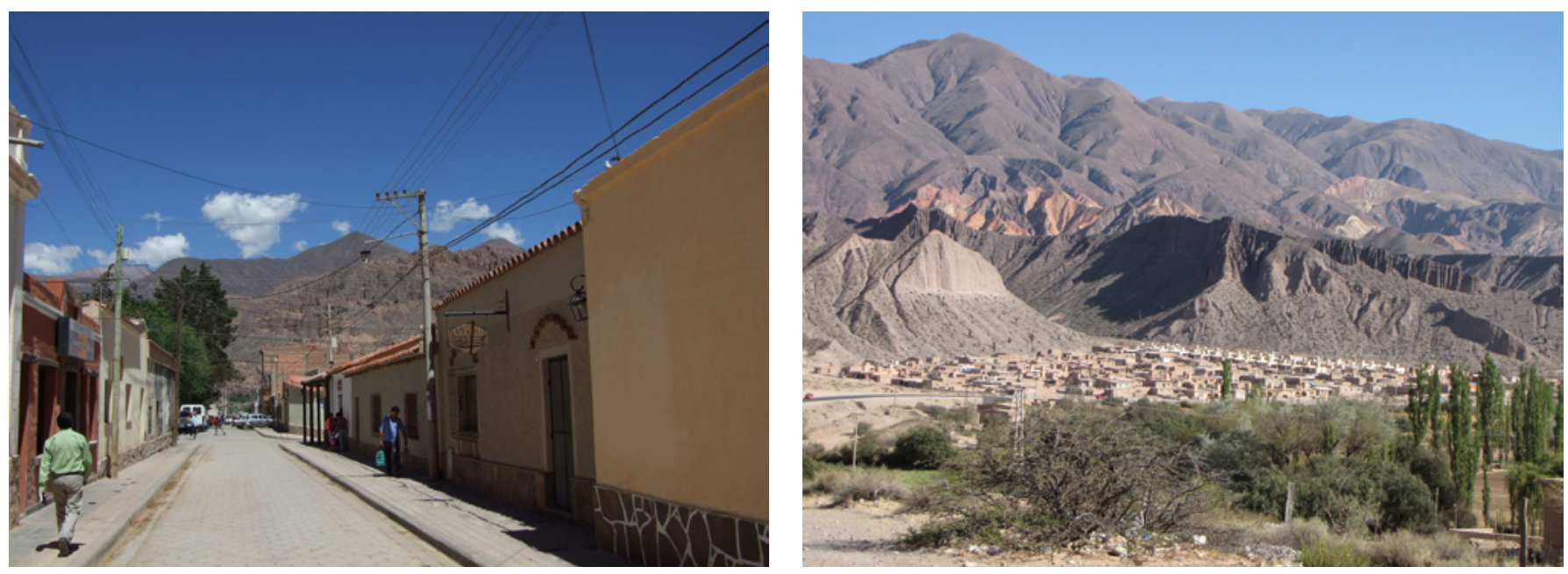


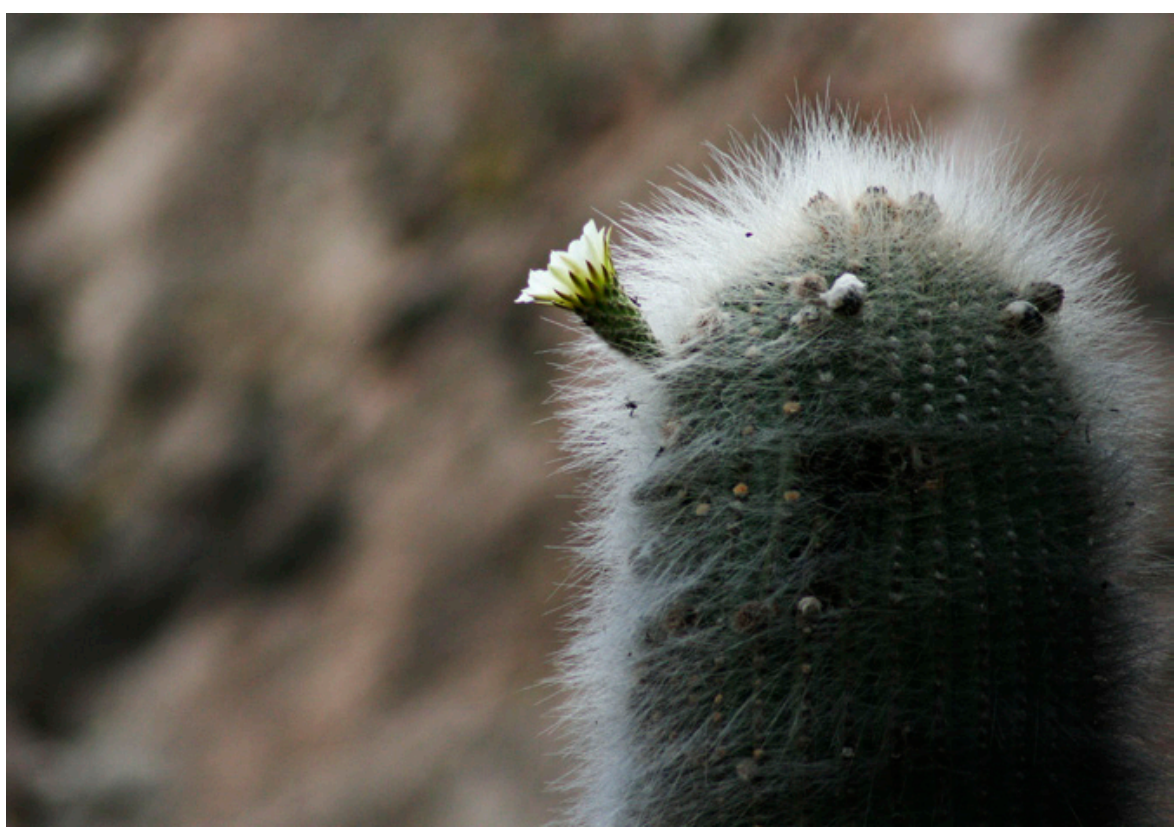

Cardón en flor, Tilcara | foto Constanza Inés Tommei

dado lo propio, como por ejemplo los programas dedicados a la producción campesina que han identificado y revalorizado a los artesanos del paisaje, aquellos que en su resistencia silenciosa han conservado desde su actividad, el saber, el color, el olor y el sabor de la biodiversidad cuando citan "Nuestro cultivos son plantas originarias de los 'Andes', acostumbrados a crecer en alturas mayores de 2000 y hasta 4000 metros de altura; allí soportan fríos, heladas, y suelos hostiles... la variedad de colores y formas representan una gran riqueza y un valioso patrimonio cultural de la alimentación" (CHOQUE VILCA, 2005: 5).

Entendemos que el desarrollo de ambos instrumentos generará importantes y diversos impactos, pues permitirá, desde lo social, a) ampliar el conocimiento consciente de los valores patrimoniales y el diseño de estrategias para su salvaguarda con la participación de los diferentes actores; b) formar recursos humanos pluridisciplinares para actuar desde el sector público y las ONG; c) optimizar el funcionamiento institucional tanto de los sistemas orgánicos y operativos como de los marcos de protección legal; d) fortalecer el conocimiento y la participación activa de las comunidades en la comprensión de los valores patrimoniales y su protección.

Desde lo ambiental, la construcción del inventario y el catálogo permitirá: a) identificar los recursos paisajísticos (culturales y naturales) de mayor interés para una adecuada protección; b) orientar actuaciones favorecedoras para evitar impactos ambientales negativos (infraestructuras, grandes equipamientos, instalaciones turísticas, etc.); c) orientar la inserción de la 
nueva arquitectura de forma armónica; d) determinar las áreas aptas para nuevas urbanizaciones, evitando, por ejemplo, los conos de deyección o el lecho de los ríos; e) fomentar la salvaguarda de los valores paisajísticos identificados.

Desde lo económico-social, permitirá: a) descubrir oportunidades de empleo que eviten las migraciones así como el fomento de proyectos de ordenamiento que lleven implícito la superación de la desigualdad, la exclusión y la pobreza al situar al territorio en condiciones de iniciar un nuevo impulso de desarrollo; b) corregir dinámicas externas que van deteriorando su identidad; c) favorecer la oportunidad de que el patrimonio se convierta en un componente activo en la generación sostenible de recursos económicos y empleos para las comunidades locales, adoptándolo como protagonista para generar nuevas estrategias para el desarrollo local y regional que permitan superar la desigualdad, la exclusión y la pobreza.

El proyecto se plantea contribuir al desarrollo de un proceso de gestión sustentado en tres pilares fundamentales: protección, ordenamiento y conservación. Entendemos que la construcción del inventario y del catálogo permitirá avanzar en el conocimiento científico y en el campo de la protección y sentará las bases para el ordenamiento y la conservación. Para ello se trabajará en la generación de procesos, herramientas o instrumentos que faciliten la construcción del inventario y del catálogo del paisaje, los que serán la base para definir unidades de paisaje y objetivos de calidad paisajística. En la etapa de protección, consideramos necesario preparar otros instrumentos vinculados a la concertación de los distintos sectores ante toda intervención, para lo que se propondrá la definición de acuerdos o cartas del paisaje, así como de instrumentos de sensibilización y educación para los habitantes o de instrumentos de financiación que den viabilidad al proceso.

Entendemos que una gestión del patrimonio que desarrolle en profundidad cada una de las fases, procesos e instrumentos planteados, permitirá reducir de forma considerable los continuos problemas que afectan a este paisaje cultural, en muchos casos debido a que el conocimiento sobre el patrimonio está circunscrito prioritariamente a los ámbitos técnicos y académicos de donde ha surgido, la documentación existente es escasa, el vocabulario interpretativo resulta ajeno al habitante $y$, sobre todo, porque se encuentra en muchos casos despojado de los valores simbólicos y significativos que la población le reconoce. Es por ello que, frente a este estado de la cuestión, observamos como eje del proyecto la necesidad de documentar el patrimonio conjuntamente con la población, de incorporar los instrumentos y métodos con los que tanto pobladores como profesionales se encuentran hoy familiarizados, encontrando en el plano digital un área común para compartir e intercambiar el conocimiento que se vaya elaborando. Entendemos que la creación de un inventario digital permitirá la difusión de lo inventariado con 
costos escasos, así como orientar las intervenciones que deban realizarse, a veces adoptando decisiones en forma inmediata, ya sea en el sector público o en el privado.

Para ello, se hace necesario formalizar el inventario y el catálogo con el más avanzado sistema de información, así como definir el rol de los técnicos, los profesionales y de los habitantes. Existen experiencias internacionales como las del Instituto Andaluz del Patrimonio Histórico o las de la Universidad Politécnica de Cataluña, a las que resulta necesario conocer y evaluar para generar el instrumento local.

La comprensión del paisaje cultural, que incluye la elaboración de procesos de gestión para su preservación, significará el uso de operaciones vinculadas a reconocer los hechos, asumir las actitudes que ellos comportan, clasificarlos y explicarlos. Importará entonces la comprensión explicativa de los fenómenos: los tipos de paisajes, la definición de sus valores, transformaciones, etc., que serán volcados en resultados concretos como el inventario y el catálogo de recursos paisajísticos. Luego se realizará el entrecruzamiento de datos con las recomendaciones propuestas por el Convenio Europeo del Paisaje (CEP) para la gestión de los mismos, con el fin de establecer los principios que debieran regir traducidos en las políticas de paisaje y pautas para un plan de paisajes. Para el análisis e interpretación de los datos se trabajará, según el proceso y etapa de la investigación, con integración de técnicas de análisis documental e histórico, observacionales (relevamientos visuales, planimétricos y fotográficos). Debido a la importancia que ha significado en las últimas décadas la inclusión de la participación comunitaria en la implementación de estrategias de desarrollo local, promovida además por el CEP, se ha puesto en movimiento metodologías participativas. Parte del grupo de trabajo ha realizado algunas experiencias en esta dirección, con la implementación de talleres guiados por profesionales del campo social; entendemos, sin embargo, que es preciso profundizar en el estudio del método de investigación participativa para aproximarnos al conocimiento del saber local.

\section{ANTECEDENTES, AVANCES Y ESTADO DEL ARTE}

El equipo responsable ha participado indistintamente en proyectos vinculados al tema, algunos que involucran a universidades europeas y latinoamericanas. Pueden mencionarse como antecedentes, por ejemplo, el Programa de Desarrollo Social y Cultural a través de la recuperación de Monumentos Históricos, de la Comisión Nacional de Monumentos y el Banco Interamericano de Desarrollo (1997), donde uno de los centros de estudio fue la quebrada de Humahuaca; el desarrollo del Formulario para la inscripción del sitio mencionado en la lista de Patrimonio Mundial (UNESCO, 

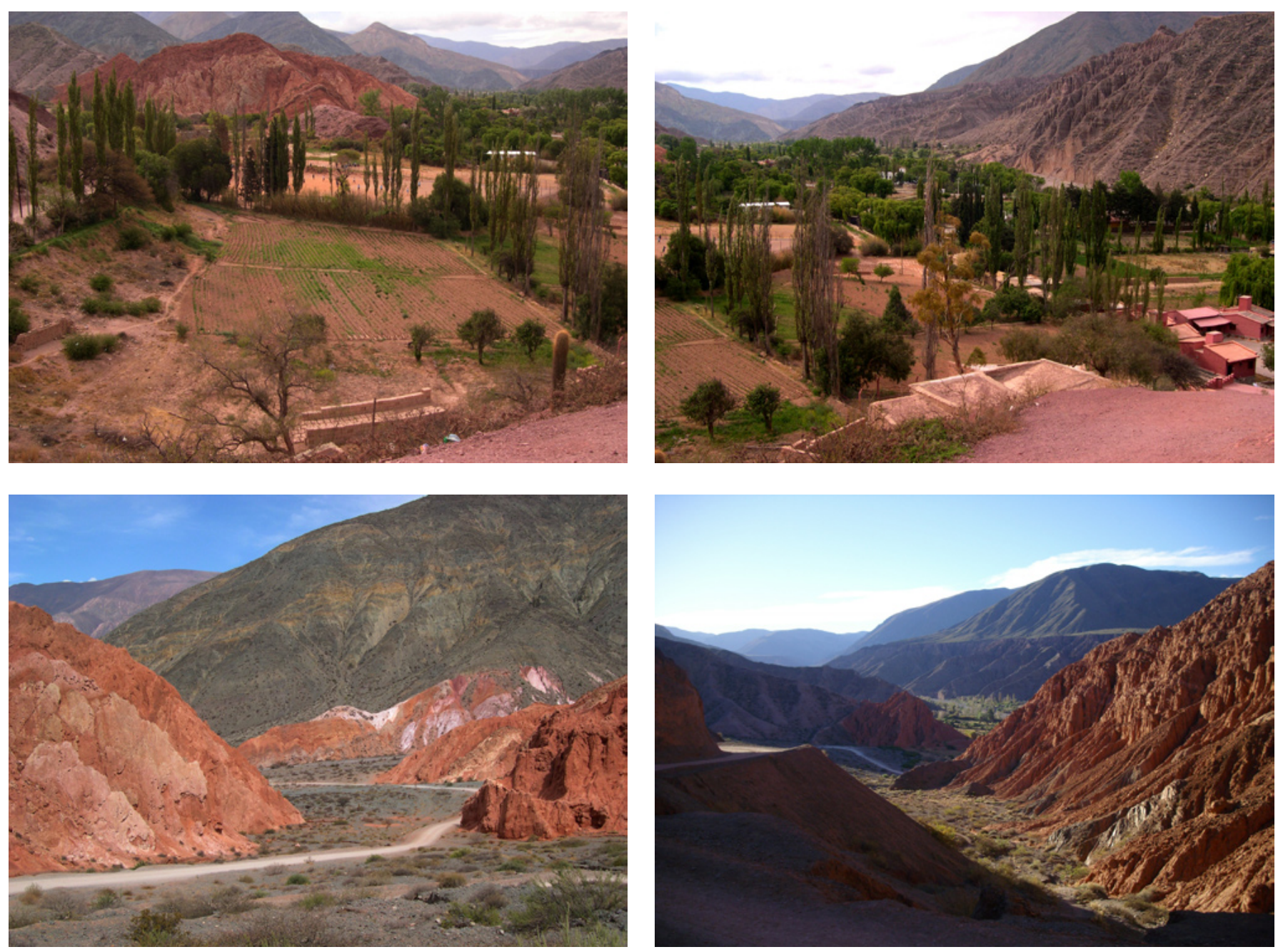

Jujuy, Pumamarca. Noviembre de 2008 | fotos Vicent Giménez

2003), que permitió su declaratoria como paisaje cultural de la humanidad; el Plan de Gestión de la Quebrada de Humahuaca, requisito de la UNESCO Cerro Los Colorados en Purmamarca | fotos Vicent Giménez (izq.) Enrique Torres Bernier (der.) al que da cumplimiento la Unidad de Gestión, 2009; el Plan de Desarrollo Turístico Sustentable para la Provincia de Jujuy, gestionado por la Secretaría de Turismo y Cultura, 2006, entre otros.

También resultan importantes como antecedentes trabajos realizados por investigadores de diversas áreas del conocimiento en referencia a la quebrada de Humahuaca. Sin embargo, en ninguno de los trabajos de los últimos años se desarrolla una investigación sobre la temática y modo de abordarla como aquí la proponemos. Esta iniciativa que trata de poner en valor los recursos culturales a partir de una idea-fuerza territorial y de elaborar nuevos criterios y proyectos para la ordenación de los paisajes culturales es de reciente formación y formulación en nuestro medio. De ahí la novedad que plantea esta investigación. 
La ejecución de catálogos de paisajes culturales se ha definido en los últimos años como uno de los instrumentos que permiten orientar la protección y ordenación del paisaje. Este hecho está documentado en algunas normativas formuladas en Cataluña, Galicia y Andalucía, en las que se fueron aplicando los principios y estrategias de acción que establece el Convenio Europeo del Paisaje promovido por el Consejo de Europa. La mayoría de estos documentos tienen como objetivo la identificación de los diferentes tipos de paisajes y el inventario de los valores paisajísticos que existen en cada área patrimonial, permitiendo detectar además, aquellos sitios o áreas que presenten un estado de deterioro y que precisen medidas de intervención y protección. En este sentido pueden mencionarse el Reglamento del Paisaje Cultural de la Comunidad Valenciana, el Catálogo abierto de paisajes singulares y sobresalientes de la CAPV-Anteproyecto, Comarques Gironines. Catàleg de paisatge, la Guía del Paisaje Cultural de la Ensenada de Bolonia en Cádiz y la metodología propuesta para el caso catalán de Prototipus de Catàleg de Paisatge.

Por último, y como avances en el tema puede mencionarse que parte del equipo de trabajo propuesto ha desarrollado: a) PFIP convocatoria 2006: Promoción del Desarrollo Turístico Sustentable a través de una legislación del Patrimonio Cultural construido en la quebrada de Humahuaca, Patrimonio Mundial; b) PFIP convocatoria 2008 Fortalecimiento del desarrollo turístico y conservación de la identidad cultural a través de la arquitectura de tierra en la quebrada de Humahuaca, Patrimonio Mundial. 2008-2010; c) PICT 2007 de Paisajes culturales y desarrollo local. Evaluación de planes, proyectos y transformaciones territoriales en la quebrada de Humahuaca y en el Camino de las Estancias, proyecto en red de cuatro universidades UBA, UNGS, UNT Y UNC. Son estos trabajos los que van haciendo la apertura hacia la comprensión teórica y la gestión de los paisajes culturales, nuevo desafío generado en esta región por la declaratoria de UNESCO. En Argentina es aún incipiente la definición de sistemas de información como el que se propone desarrollar, por lo cual su implementación podría replicarse con alto rendimiento en otros paisajes culturales para su protección.

Nota de la redacción revista ph

Agradecemos a las siguientes personas su colaboración en esta sección aportando imágenes de la Quebrada de Humahuaca que fueron publicadas en el perfil de Facebook del IAPH entre los meses de abril y junio de 2013:

Vicent Giménez Chornet | Alejo Gutiérrez Viñuales | Martín Gutiérrez Viñuales | Constanza Inés Tommei | Enrique Torres Bernier | Iván Velasco Romera 


\section{BIBLIOGRAFÍA}

- BosCHI, L.; NIELSEN, A. (2004) Quebrada de Humahuaca. Un itinerario cultural con 10.000 años de historia. Gobierno de Jujuy. San Salvador de Jujuy: CFI, 2004

- CHOQUE VILCA, M. (coord.) (2005) Sintiendo la diversidad. En Sabores de ayer en la mesa de hoy. San Salvador de Jujuy: Fundandes, 2005

- DECRETO 120/2006, de 11 agosto, Reglamento de Paisaje de Comunidad Valenciana. Diari Oficial de la Comunitat Valenciana, n. ${ }^{\circ}$ 5325, de 16 agosto 2006

- IKT-PAISAIA (2005) Catálogo abierto de paisajes Singulares y sobresalientes de la CAPV - Anteproyecto. Gobierno Vasco, Departamento de Medio Ambiente y Ordenación del Territorio, Dirección de Biodiversidad y Participación Ambiental, 2005

- JosÉ, N. et ál. (2002) Quebrada de Humahuaca. Un Itinerario Cultural de 10.000 años. Propuesta para la Inscripción a la Lista de Patrimonio Mundial de la UNESCO. Jujuy: Gobierno de la Provincia de Jujuy, 2002

- NICOLINI, A; PATERLINI, O.; SILVA, M. et ál. (1997) Programa de Desarrollo Social y Cultural a través de la recuperación de Monumentos Históricos. Área Patrimonio del NOA. Proyecto BID convocatoria 1991 (inédito)

- NOGUÉ, J.; SALA, P. (2006) Prototipus de catàleg de paisatge: bases conceptuals, metodològiques $i$ procedimentals per elaborar els catàlegs de paisatge de Catalunya: document de referència per als grups de treball (edició revisada). Olot i Barcelona: Observatori del Paisatge, 2006

- OBSERVATORI DEL PAISATGE (coord.) (2010) Comarques Gironines. Catàleg de paisatge. Girona: Generalitat de Catalunya. Departament de Política Territorial i Obres Públiques, 2010

- PATERLINI, O.; FERRARI, M. (2011) La conservación del paisaje cultural: Propuesta de legislación para la Quebrada de Humahuaca, Jujuy, Patrimonio Mundial. En Jornadas El Patrimonio Urbano y Arquitectónico: la gestión para su conservación. San Miguel de Tucumán: ICOMOS Argentina e Instituto de Historia y Patrimonio de la FAU - UNT, 2011

- PATERLINI, O. (2012) La protección del territorio como paisaje cultural: el caso de la Quebrada de Humahuaca en Jujuy. En Paisajes Culturales. Jornadas de reflexión acerca de los paisajes culturales de Argentina y Chile, en especial los situados en la región patagónica. Río Gallegos: Universidad Nacional de la Patagonia Austral, Universidad de Magallanes, Chile y Comité Argentino de ICOMOS, grupo Patagonia, 2012
- ROTONDARO,R. etál.(2012)Propuestasparaconservar la Arquitectura de Tierra de la Quebrada de Humahuaca, Jujuy, Argentina. En XI Conferencia Internacional sobre el Estudio y Conservación del Patrimonio Arquitectónico de Tierra, Terra 2012. Lima: Comité Científico Internacional del Patrimonio en Tierra (ICOMOS/ISCEAH), la Pontificia Universidad Católica del Perú (PUCP), 2012

- SALMERóN, P. (coord.) (2004) Guía del paisaje cultural de la Ensenada de Bolonia, Cádiz. Avance. Sevilla: Junta de Andalucía. Consejería de Cultura. Instituto Andaluz del Patrimonio Histórico, 2004 (Colección PH Cuadernos, n. ${ }^{\circ}$ 16) 